\title{
Short-Term Changes in Ambient Temperature and Risk of Ischemic Stroke
}

\author{
Elizabeth Mostofsky a, b Elissa H. Wilker ${ }^{a} \quad$ Joel Schwartz ${ }^{b, c}$ \\ Antonella Zanobettic Diane R. Gold ${ }^{c, d}$ Gregory A. Wellenius ${ }^{e}$ \\ Murray A. Mittleman ${ }^{a, b}$ \\ ${ }^{a}$ Cardiovascular Epidemiology Research Unit, Department of Medicine, Beth Israel \\ Deaconess Medical Center, Harvard Medical School, and Departments of ${ }^{b}$ Epidemiology \\ and ${ }^{\mathrm{C} E n v i r o n m e n t a l ~ H e a l t h, ~ H a r v a r d ~ S c h o o l ~ o f ~ P u b l i c ~ H e a l t h, ~}{ }^{\mathrm{d} C h a n n i n g ~ L a b o r a t o r y, ~}$ \\ Department of Medicine, Brigham and Women's Hospital, Boston, Mass., and ${ }^{\mathrm{D}}$ Department \\ of Epidemiology, School of Public Health, Brown University, Providence, R.I., USA
}

\author{
Key Words \\ Ischemic stroke $\cdot$ Environment $\cdot$ Particulate matter $\cdot$ Epidemiology
}

\section{Abstract}

Background: Despite consistent evidence of a higher short-term risk of cardiovascular mortality associated with ambient temperature, there have been discrepant findings on the association between temperature and ischemic stroke. Moreover, few studies have considered potential confounding by ambient fine particulate matter air pollution $<2.5 \mu \mathrm{m}$ in diameter $\left(\mathrm{PM}_{2.5}\right)$ and none have examined the impact of temperature changes on stroke in the subsequent hours rather than days. The aim of this study was to evaluate whether changes in temperature trigger an ischemic stroke in the following hours and days and whether humid days are particularly harmful. Methods: We reviewed the medical records of 1,705 patients residing in the metropolitan region of Boston, Mass., USA, who were hospitalized with neurologistconfirmed ischemic stroke, and we abstracted data on the time of symptom onset and clinical characteristics. We obtained hourly meteorological data from the National Weather Service station and hourly $\mathrm{PM}_{2.5}$ data from the Harvard ambient monitoring station. We used the time-stratified case-crossover design to assess the association between ischemic stroke and apparent temperature averaged over 1-7 days prior to stroke onset adjusting for $\mathrm{PM}_{2.5}$. We assessed whether differences in apparent temperature trigger a stroke within shorter time periods by examining the association between stroke onset and apparent temperature levels averaged in 2-hour increments prior to stroke onset (0-2 h through 36-38 h). We tested whether the association varied by health characteristics or by $\mathrm{PM}_{2.5}$, ozone or relative humid- 
ity. Results: The incidence rate ratio of ischemic stroke was 1.09 (95\% confidence interval 1.01-1.18) following a $5^{\circ} \mathrm{C}$ decrement in average apparent temperature over the 2 days preceding symptom onset. The higher risk associated with cooler temperatures peaked in the first 14-34 h. There was no statistically significant difference in the association between temperature and ischemic stroke across seasons. The risk of ischemic stroke was not meaningfully different across subgroups of patients defined by health characteristics. The association between ischemic stroke and ambient temperature was stronger on days with higher levels of relative humidity. Conclusions: Lower temperatures are associated with a higher risk of ischemic stroke onset in both warm and cool seasons, and the risk is higher on days with higher levels of relative humidity. Based on this study and the body of literature on ambient temperature and cardiovascular events, identifying methods for mitigating cardiovascular risk may be warranted.

(c) 2014 S. Karger AG, Basel

\section{Background}

There is consistent evidence of a higher short-term risk of myocardial infarction [1] and cardiovascular mortality [2] associated with changes in ambient temperature. However, there have been discrepant findings on the association between temperature and ischemic stroke hospitalization in the subsequent days and weeks, studies showing that there is a higher risk of ischemic stroke following increases [3-13], decreases [5, 14-19], differences in the minimum/maximum temperature $[16,20]$ or within-day variability [21] in average temperature, and others failing to find any association [22-26]. Despite evidence on the association between air pollution and stroke $[27,28]$ and other cardiovascular outcomes [29], most prior studies on weather and stroke risk have ignored potential confounding by ambient fine particulate matter air pollution $<2.5 \mu \mathrm{m}$ in diameter $\left(\mathrm{PM}_{2.5}\right)$ and none have examined the acute impact of temperature changes on stroke in the subsequent hours rather than days.

In this study, we hypothesized that changes in temperature within a single metropolitan area would be associated with an acutely higher risk of ischemic stroke in the following hours and days. Furthermore, we hypothesized that humid days would be particularly harmful.

\section{Methods}

\section{Case Ascertainment}

This study was approved by the Institutional Review Board at the Beth Israel Deaconess Medical Center (BIDMC). We identified potentially eligible patients for this study by reviewing daily emergency department admission logs, stroke service admission logs, stroke service consult logs, and hospital electronic discharge records. There were 1,763 consecutive patients $\geq 21$ years of age admitted to the BIDMC between April 1, 1999 and October 31, 2008, with neurologist-confirmed ischemic stroke and residing in the metropolitan region of Boston, Mass., USA, as previously described [28]. Patients with in-hospital strokes or transient ischemic attacks were excluded. Trained abstractors recorded data on patient demographics, presenting symptoms and medical history from medical records. When the date of stroke onset was known but the time could not be estimated $(n=221)$, we assumed that symptom onset occurred at 9 a.m. We excluded $58(3 \%)$ patients for whom neither the date nor the time of stroke onset was documented, resulting in 1,705 patients available for analysis. 


\section{Exposure Assessment}

We obtained hourly meteorological data, including temperature, relative humidity, and barometric pressure, from the National Weather Service station at Boston's Logan Airport and calculated apparent temperature, an index of thermal comfort that takes into account the effect of humidity on the body [30]. For comparability with prior studies [7, 8], we examined the stroke risk associated with a $5^{\circ} \mathrm{C}$ change in mean temperature or apparent temperature.

We obtained hourly measurements of $\mathrm{PM}_{2.5}$ from the Harvard - US Environmental Protection Agency Supersite in Boston, located $<1 \mathrm{~km}$ from the study site, as previously described [31]. We obtained hourly measures of ozone from local state monitors managed by the Department of Environmental Protection.

\section{Statistical Analysis}

We used the time-stratified case-crossover study design [32,33] to assess the association between ischemic stroke and weather in the $24 \mathrm{~h}$ preceding each event. In this design, each subject's exposure prior to a case-defining event (case period) is compared with his or her exposure during periods when the subject did not become a case (control period). Exposure during the $24 \mathrm{~h}$ preceding each event were compared to levels on other days of the same month, day and hour of the day as the case period. This design has been shown to effectively control for seasonality, time trends, and chronic and slowly varying potential confounders [34].

We performed conditional logistic regression stratifying on hospitalization to obtain estimates of odds ratios (OR) and $95 \%$ confidence intervals (CI). Because of the sampling strategy, these OR are unbiased estimates of the incidence rate ratio (IRR). For all analyses, we calculated estimates for the entire year and separately for spring (April to May), summer (June to August), fall (September to November) and winter (December to March).

In the primary analyses, we used apparent temperature as the exposure of interest since public health agencies and weather stations report this measure as an indicator of discomfort as a function of temperature and humidity. In the analyses to evaluate whether humidity confounds or modifies the association between temperature and ischemic stroke, we used temperature, relative humidity and their interaction in the same model to test their independent impact on ischemic stroke.

We examined the impact of changes in apparent temperature averaged over 1-7 days prior to stroke onset. We assessed whether differences in apparent temperature trigger a stroke within shorter time periods by examining the association between stroke onset and apparent temperature levels averaged in 2-hour increments prior to stroke onset $(0-2 \mathrm{~h}$ through 36-38 h). We conducted exploratory analyses to determine whether the use of linear temperature terms was appropriate by fitting the models using natural cubic splines with 3 degrees of freedom for apparent temperature. Upon visual inspection of the exploratory plots, the association appeared linear over the range of observed temperatures, so we used linear temperature terms to facilitate the reporting of IRRs. We evaluated the impact of adjusting for $\mathrm{PM}_{2.5}$, ozone and relative humidity using linear terms with the same lag as the temperature term. Because variation in temperature from the long-term average is associated with cardiovascular risk [35], we evaluated the association between stroke risk and within-day variability in apparent temperature, the deviation of apparent temperature from the average apparent temperature at that time over the 10-year study period, and the change in temperature above the 95th percentile and below the 5 th percentile for each season.

We tested whether the association between temperature and stroke varied across season by testing the significance of interaction terms for apparent temperature and indicator variables for season. Because the association between temperature and ischemic stroke was most robust and precisely estimated over a 2-day moving average, we tested whether the associ- 


\section{Cerebirovascular \\ Diseases}

Table 1. Clinical characteristics of 1,705 patients hospitalized for acute ischemic stroke (19992008)

\begin{tabular}{l|l}
\hline Cerebrovasc Dis Extra 2014;4:9-18 \\
\hline DOI: 10.1159/000357352 & $\begin{array}{l}\text { @ 2014 S. Karger AG, Basel } \\
\text { www.karger.com/cee }\end{array}$ \\
\hline
\end{tabular}

Mostofsky et al.: Short-Term Changes in Ambient Temperature and Risk of Ischemic Stroke

$\begin{array}{lr}\text { Age, years } & 73.1 \pm 14.5 \\ \text { Female gender } & 931(54.6) \\ \text { White ethnicity } & 1,165(68.3) \\ \text { Past medical history } & \\ \quad \text { Stroke or TIA } & 482(28.3) \\ \quad \text { Atrial fibrillation } & 424(24.9) \\ \quad \text { Hypertension } & 1,216(71.3) \\ \quad \text { Coronary artery disease } & 432(25.3) \\ \quad \text { Heart failure } & 221(13.0) \\ \quad \text { Diabetes mellitus } & 495(29.0) \\ \text { COPD } & 105(6.2) \\ \text { Smoking history } & \\ \quad \text { Current } & 236(13.8) \\ \text { Former } & 457(26.8)\end{array}$

Values are $\mathrm{n}(\%)$ or means \pm SD. TIA $=$ Transient ischemic attack; COPD $=$ chronic obstructive pulmonary disease.

ation between ischemic stroke and average apparent temperature in the prior 2 days was modified by $\mathrm{PM}_{2.5}$ or ozone and whether the association between ischemic stroke onset and average ambient temperature in the prior 2 days was modified by relative humidity by testing the significance of interaction terms. We also tested whether the association between temperature and stroke varied by sex, age ( $<65$ vs. $\geq 65$ ), smoking history (current, former, never), history of diabetes mellitus, hypertension or atrial fibrillation and presumed stroke pathophysiologic mechanism (categorized as large-artery atherosclerosis, small-vessel occlusion, cardioembolism, other determined cause or undetermined cause, using the approach developed for the Trial of ORG 10172 in Acute Stroke Treatment) [36] by analyzing the statistical significance of interaction terms. If there was statistical evidence of an interaction, we estimated the association and $95 \%$ profile likelihood $\mathrm{CI}$ at the 5 th and 95 th percentile of the modifier. A two-sided $\mathrm{p}$ value of 0.05 was considered statistically significant. Analyses were performed using SAS version 9.2 (SAS Institute Inc.) and the R statistical package, version 2.8.1 [37].

\section{Results}

Among the 1,705 patients admitted with a confirmed ischemic stroke, most were women and most had a history of hypertension (table 1). The weather characteristics for the days included in this analysis are described in table 2. There was a higher risk of ischemic stroke when the average apparent temperature over the days prior to stroke onset was lower than other times (fig. 1). In models adjusted for $\mathrm{PM}_{2.5}$, the rate for ischemic stroke was $7 \%(95 \%$ CI 0-15) higher per $5{ }^{\circ} \mathrm{C}$ decrement in apparent temperature over the past day and $9 \%(95 \%$ CI 1-18) higher over the past 2 days. In models not adjusted for $\mathrm{PM}_{2.5}$, this remained statistically significant for a 7-day moving average, but in models adjusted for $\mathrm{PM}_{2.5}$, the association was statistically significant for up to a 4-day moving average. The higher stroke risk peaked in the 10-24 $\mathrm{h}$ following the decrement in apparent temperature and began to decline thereafter (fig. 2). There was no statistically significant interaction by season; the associations between temperature and ischemic stroke were similar in all seasons, except in the fall, when no association was observed. The results did not differ materially when we adjusted for $\mathrm{PM}_{2.5}$, ozone or relative humidity. There was no association between ischemic stroke and other measures of temperature change. 
Table 2. Weather characteristics for Boston, Mass., USA (January 1999 to September 2008)

\begin{tabular}{|c|c|c|c|c|c|c|c|}
\hline Season & Days & Variable & $\begin{array}{l}\text { Mini- } \\
\text { mum }\end{array}$ & $\begin{array}{l}\text { Maxi- } \\
\text { mum }\end{array}$ & Mean & $\begin{array}{l}\text { Standard } \\
\text { deviation }\end{array}$ & Median \\
\hline \multirow[t]{2}{*}{$\begin{array}{l}\text { Spring (April, } \\
\text { May) }\end{array}$} & \multirow[t]{2}{*}{610} & $\begin{array}{l}\text { Temperature, }{ }^{\circ} \mathrm{C} \\
\text { Apparent temperature, }{ }^{\circ} \mathrm{C}\end{array}$ & $\begin{array}{l}-0.21 \\
-2.7\end{array}$ & $\begin{array}{l}28.44 \\
28.11\end{array}$ & $\begin{array}{r}11.27 \\
9.39\end{array}$ & $\begin{array}{l}4.92 \\
5.43\end{array}$ & $\begin{array}{r}10.76 \\
8.66\end{array}$ \\
\hline & & $\begin{array}{l}\text { Relative humidity, \% } \\
\mathrm{PM}_{2.5}, \mu \mathrm{g} / \mathrm{m}^{3}\end{array}$ & $\begin{array}{r}24.54 \\
2.25 \\
\end{array}$ & $\begin{array}{l}100 \\
33.53\end{array}$ & $\begin{array}{r}66.13 \\
8.48 \\
\end{array}$ & $\begin{array}{r}18.38 \\
4.33 \\
\end{array}$ & $\begin{array}{r}65.00 \\
7.44 \\
\end{array}$ \\
\hline \multirow[t]{2}{*}{$\begin{array}{l}\text { Summer (June, } \\
\text { July, August) }\end{array}$} & \multirow[t]{2}{*}{920} & $\begin{array}{l}\text { Temperature, }{ }^{\circ} \mathrm{C} \\
\text { Apparent temperature, }{ }^{\circ} \mathrm{C}\end{array}$ & $\begin{array}{l}9.72 \\
8.38\end{array}$ & $\begin{array}{l}31.34 \\
35.85\end{array}$ & $\begin{array}{l}21.62 \\
22.79\end{array}$ & $\begin{array}{l}3.88 \\
5.15\end{array}$ & $\begin{array}{l}21.81 \\
22.87\end{array}$ \\
\hline & & $\begin{array}{l}\text { Relative humidity, } \% \\
\mathrm{PM}_{2.5}, \mu \mathrm{g} / \mathrm{m}^{3}\end{array}$ & $\begin{array}{r}30.54 \\
2.14 \\
\end{array}$ & $\begin{array}{r}100 \\
75.89\end{array}$ & $\begin{array}{l}70.92 \\
12.83\end{array}$ & $\begin{array}{r}13.51 \\
8.03\end{array}$ & $\begin{array}{l}70.63 \\
10.62 \\
\end{array}$ \\
\hline \multirow[t]{2}{*}{$\begin{array}{l}\text { Fall (September, } \\
\text { October, } \\
\text { November) }\end{array}$} & \multirow[t]{2}{*}{849} & $\begin{array}{l}\text { Temperature, }{ }^{\circ} \mathrm{C} \\
\text { Apparent temperature, }{ }^{\circ} \mathrm{C} \\
\text { Relative humidity, } \%\end{array}$ & $\begin{array}{l}-3.91 \\
-4.79 \\
33.45\end{array}$ & $\begin{array}{l}27.61 \\
30.97 \\
100\end{array}$ & $\begin{array}{l}13.21 \\
12.22 \\
70.78\end{array}$ & $\begin{array}{l}6.06 \\
7.3 \\
14.23\end{array}$ & $\begin{array}{l}13.43 \\
11.89 \\
71\end{array}$ \\
\hline & & $\mathrm{PM}_{2.5}, \mu \mathrm{g} / \mathrm{m}^{3}$ & 0.94 & 36.21 & 9.18 & 5.25 & 7.79 \\
\hline \multirow[t]{2}{*}{$\begin{array}{l}\text { Winter (December, } \\
\text { January, February, } \\
\text { March) }\end{array}$} & \multirow[t]{2}{*}{1,092} & $\begin{array}{l}\text { Temperature, }{ }^{\circ} \mathrm{C} \\
\text { Apparent temperature, }{ }^{\circ} \mathrm{C} \\
\text { Relative humidity, } \%\end{array}$ & $\begin{array}{r}-18.33 \\
-9.83 \\
20.66\end{array}$ & $\begin{array}{l}17.24 \\
17.04 \\
100\end{array}$ & $\begin{array}{r}0.97 \\
-0.19 \\
62.79\end{array}$ & $\begin{array}{r}5.3 \\
4.08 \\
16.69\end{array}$ & $\begin{array}{r}1.18 \\
-0.74 \\
60.66\end{array}$ \\
\hline & & $\mathrm{PM}_{2.5}, \mu \mathrm{g} / \mathrm{m}^{3}$ & 0.94 & 32.8 & 9.59 & 4.51 & 8.51 \\
\hline
\end{tabular}

Fig. 1. IRR of ischemic stroke onset per $5^{\circ} \mathrm{C}$ decrease in the moving average of apparent temperature in the days preceding stroke onset. There was no statistical evidence showing that the association between temperature and stroke varied across seasons.

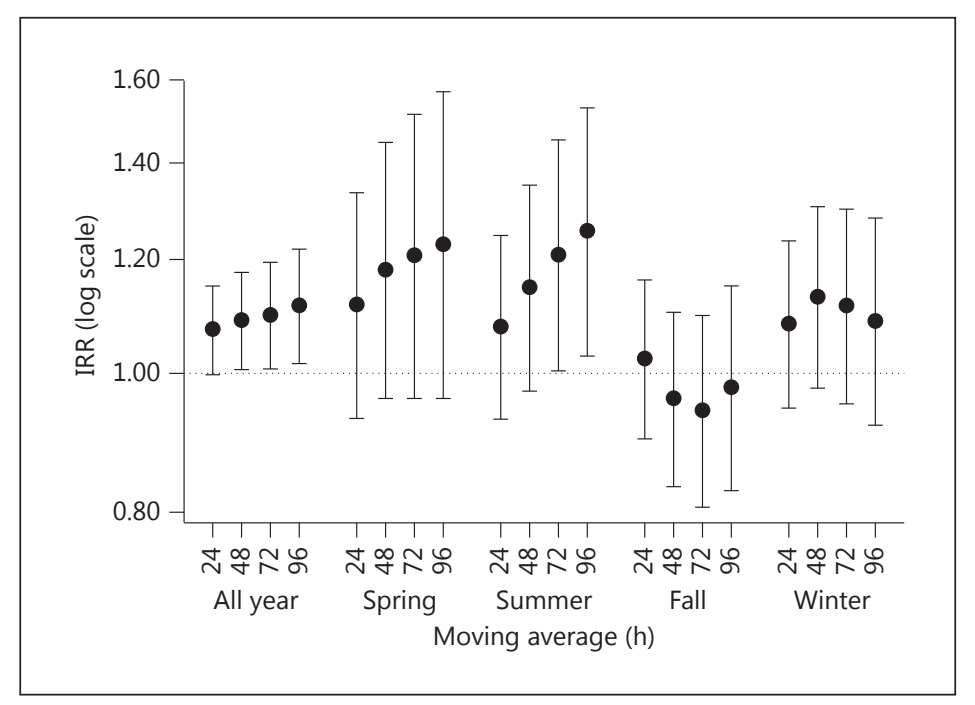

The association between temperature and ischemic stroke varied by levels of relative humidity ( $\mathrm{p}$ for interaction $=0.02$ ). On dry days $(5$ th percentile $=41 \%$ relative humidity), $\mathrm{a}$ $5^{\circ} \mathrm{C}$ decrement in temperature was not associated with a higher risk of ischemic stroke $($ IRR $=0.97 ; 95 \%$ CI $0.91-1.05$ ), but on more humid days (95th percentile $=93 \%$ relative humidity), lower temperature was associated with a higher risk (IRR $=1.11$; 95\% CI 1.001.23). The association between apparent temperature and stroke was not modified by $\mathrm{PM}_{2.5}$ or ozone. The risk of ischemic stroke was not meaningfully different across subgroups of patients defined by health characteristics or presumed stroke pathophysiologic mechanism. 
Fig. 2. IRR of ischemic stroke onset per $5^{\circ} \mathrm{C}$ decrease in apparent temperature for each 2-hour interval on the day preceding stroke onset.

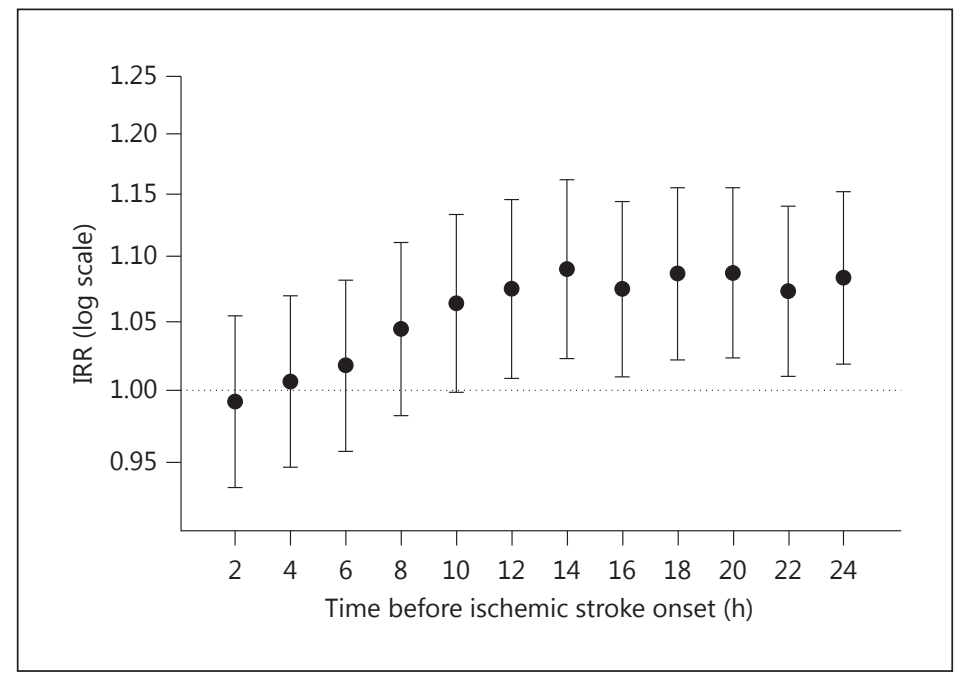

\section{Discussion}

In this case-crossover study of 1,705 patients residing in the Boston metropolitan area admitted with acute ischemic stroke, there was a higher risk of acute ischemic stroke in the hours and days following colder temperatures even after adjusting for $\mathrm{PM}_{2.5}$. This association did not differ significantly across seasons, with similar estimated associations in summer and winter. Our study adds to the literature by showing that the higher risk occurs immediately within hours and not just subsequent days, that the association remains even after adjusting for $\mathrm{PM}_{2.5}$ and ozone, and that the association is stronger at times with higher relative humidity. The evidence of an association within hours emphasizes the importance of obtaining the time of symptom onset rather than admission dates, which is all that is usually available in administrative data.

Since there is consistent evidence that heat waves are associated with a higher risk of cardiovascular events [38], it may seem likely that in the summer, lower temperatures would be associated with lower stroke risk. However, we found that even in the summer, cooler temperatures were associated with higher risk of ischemic stroke. Perhaps this is because individuals may be more likely to stay inside and use air conditioning when it is extremely hot, and therefore, they are less likely to experience the adverse effects of extreme heat levels $[11,20]$.

Overall, our results are consistent with prior studies showing that colder temperatures are associated with heightened stroke risk [5-7, 14, 20]. For instance, in a study of women from 17 countries that were observed from February 1989 to January 1995, a 5-unit increase in mean temperature was associated with a lower risk of ischemic stroke (IRR $=0.92 ; 95 \%$ CI 0.85-0.99) [7]. Similarly, in a study of 1,929 patients that experienced their first ischemic stroke, the IRR was 1.32 (95\% CI 1.05-1.66) on days with low ambient temperature $\left(\leq-2.0^{\circ} \mathrm{C}\right)$ compared to days with high ambient temperature $\left(\geq 7.3^{\circ} \mathrm{C}\right)[5]$.

Most [13, 35, 39-41] but not all [2] prior studies have found little evidence that the association between temperature and mortality is confounded by air pollution. In our study, apparent temperature was not strongly related to $\mathrm{PM}_{2.5}$ (Spearman correlation $=0.27$ ) or ozone (Spearman correlation $=0.41$ ). Therefore, it is not surprising that further adjustment for these factors did not result in materially different estimates. We found that the inverse association between temperature and ischemic stroke was modified by level of relative 
humidity. In our study, there was no association between temperature and stroke risk on dry days, but on more humid days, lower temperature was associated with a higher risk of ischemic stroke. In contrast, Ohshige et al. [14] reported a higher risk of ischemic and hemorrhagic strokes on days with low temperature and low humidity. Further research is necessary to evaluate whether there are cardiovascular risks associated with other meteorological factors, such as boundary layer disturbance.

There are several mechanisms that may explain the link between colder temperatures and ischemic stroke. Exposure to cold increases vasoconstriction and blood pressure, platelet count, cholesterol, heart rate, plasma fibrinogen, platelet viscosity and peripheral vasoconstriction [42-45]. Ambient temperature also influences markers of inflammation [45, 46], which may be associated with the longer-term higher risks from weather changes.

Based on this study and the body of literature on ambient temperature and cardiovascular events, identifying methods for mitigating this risk may be warranted. For instance, although an individual cannot completely avoid exposure to cold temperatures, perhaps individuals with existing cardiovascular disease and those at heightened risk of stroke should reduce prolonged exposure to outdoor cold or at least wear warm clothing [47].

The study has some limitations. First, the data were limited to one city, so the results may only be generalizable to regions with similar weather characteristics. Second, weather and $\mathrm{PM}_{2.5}$ information was collected at monitoring stations so it may not represent individual exposures. However, public health interventions such as weather warnings to at-risk individuals would be based on ambient rather than personal weather information. Therefore, this serves as a relevant exposure measure. Weather data from a single monitoring station may result in exposure misclassification for individuals living far from the monitoring sites, but we restricted the study to individuals living within $40 \mathrm{~km}$ of the air pollution monitors. Furthermore, a recent study showed that there is a high correlation between ambient temperature measurements at several monitors in New England, USA, suggesting that a single monitor adequately describes temporal fluctuations in temperature across New England [48]. One study used both airport monitoring data and a spatial model to estimate temperatures at place of residence as a predictor of all-cause mortality, and the results for the two exposure metrics were similar [49]. Therefore, any bias from exposure misclassification is expected to be small. Nonetheless, we cannot account for variability in temperature exposure due to differences in the amount of time spent indoors and the use of air conditioning [11, 41, 50], which would lead to a bias toward observing no association, but would not lead to a bias away from the null. We do not have information on the location of each participant at the time of stroke onset, but most subjects spend more of their time at or near their homes than at other locations. One study [51] found that Americans spend an average of $68 \%$ of their time at home. Furthermore, since recruitment took place at a single medical center and was restricted to subjects living within $40 \mathrm{~km}$ of the monitoring site, it is unlikely that many subjects were much farther away at the time of stroke onset. Therefore, any exposure misclassification should be minimal.

Despite these limitations, this study has many strengths. It includes a relatively large sample of ischemic stroke patients with information on clinical characteristics. In addition, most prior studies assessed meteorological conditions and stroke symptom onset based on the calendar day of hospital admission so they cannot examine acute changes in risk in the hours following temperature changes, and using the day rather than the hour of symptom onset may result in exposure misclassification and a bias toward the null. However, in this study, we collected information on the hour of stroke symptom onset and showed that the heightened risk occurs within hours of a decrement in apparent temperature. 
Mostofsky et al.: Short-Term Changes in Ambient Temperature and Risk of Ischemic
Stroke

\section{Conclusion}

In this case-crossover study of 1,705 patients admitted for confirmed ischemic stroke, there was a higher risk of ischemic stroke in the hours and days following moderate decrements in apparent temperature compared to times with higher temperatures. The risk associated with cooler temperatures is stronger on days with higher relative humidity.

\section{Acknowledgments}

This work was supported by the National Heart, Lung, and Blood Institute (grants T32-HL098048 and F32-HL120505), the National Institute of Environmental Health Sciences (grants P01-ES009825, P30-ES000002, R00-ES015774, and R21-ES020194), and the US Environmental Protection Agency (RD-834798).

\section{Disclosure Statement}

The authors have no conflicts of interest to disclose.

The content is solely the responsibility of the authors and does not necessarily represent the official views of the National Institutes of Health or the Environmental Protection Agency.

\section{References}

1 Bhaskaran K, Hajat S, Haines A, Herrett E, Wilkinson P, Smeeth L: Effects of ambient temperature on the incidence of myocardial infarction. Heart 2009;95:1760-1769.

-2 Basu R: High ambient temperature and mortality: a review of epidemiologic studies from 2001 to 2008. Environ Health 2009;8:40.

-3 Berginer VM, Goldsmith J, Batz U, Vardi H, Shapiro Y: Clustering of strokes in association with meteorologic factors in the Negev desert of Israel: 1981-1983. Stroke 1989;20:65-69.

4 Woo J, Kay R, Nicholls MG: Environmental temperature and stroke in a subtropical climate. Neuroepidemiology 1991;10:260-265.

5 Feigin VL, Nikitin YP, Bots ML, Vinogradova TE, Grobbee DE: A population-based study of the associations of stroke occurrence with weather parameters in Siberia, Russia (1982-92). Eur J Neurol 2000;7:171-178.

-6 Hong YC, Rha JH, Lee JT, Ha EH, Kwon HJ, Kim H: Ischemic stroke associated with decrease in temperature. Epidemiology 2003;14:473-478.

7 Chang CL, Shipley M, Marmot M, Poulter N: Lower ambient temperature was associated with an increased risk of hospitalization for stroke and acute myocardial infarction in young women. J Clin Epidemiol 2004;57:749757.

-8 Kyobutungi C, Grau A, Stieglbauer G, Becher H: Absolute temperature, temperature changes and stroke risk: a case-crossover study. Eur J Epidemiol 2005;20:693-698.

-9 Low RB, Bielory L, Qureshi AI, Dunn V, Stuhlmiller DF, Dickey DA: The relation of stroke admissions to recent weather, airborne allergens, air pollution, seasons, upper respiratory infections, and asthma incidence, September 11, 2001, and day of the week. Stroke 2006;37:951-957.

-10 Dawson J, Weir C, Wright F, Bryden C, Aslanyan S, Lees K, Bird W, Walters M: Associations between meteorological variables and acute stroke hospital admissions in the West of Scotland. Acta Neurol Scand 2008;117: 85-89.

11 Ostro B, Rauch S, Green R, Malig B, Basu R: The effects of temperature and use of air conditioning on hospitalizations. Am J Epidemiol 2010;172:1053-1061.

-12 Wang XY, Barnett AG, Yu W, FitzGerald G, Tippett V, Aitken P, Neville G, McRae D, Verrall K, Tong S: The impact of heatwaves on mortality and emergency hospital admissions from non-external causes in Brisbane, Australia. Occup Environ Med 2012;69:163-169.

13 Basu R, Pearson D, Malig B, Broadwin R, Green R: The effect of high ambient temperature on emergency room visits. Epidemiology 2012;23:813-820.

14 Ohshige K, Hori Y, Tochikubo O, Sugiyama M: Influence of weather on emergency transport events coded as stroke: Population-based study in Japan. Int J Biometeorol 2006;50:305-311.

15 Jimenez-Conde J, Ois A, Gomis M, Rodriguez-Campello A, Cuadrado-Godia E, Subirana I, Roquer J: Weather as a trigger of stroke. Daily meteorological factors and incidence of stroke subtypes. Cerebrovasc Dis 2008;26: 348-354. 
Mostofsky et al.: Short-Term Changes in Ambient Temperature and Risk of Ischemic Stroke

16 Magalhaes R, Silva MC, Correia M, Bailey T: Are stroke occurrence and outcome related to weather parameters? Results from a population-based study in Northern Portugal. Cerebrovasc Dis 2011;32:542-551.

17 Wang YC, Lin YK, Chuang CY, Li MH, Chou CH, Liao CH, Sung FC: Associating emergency room visits with first and prolonged extreme temperature event in Taiwan: a population-based cohort study. Sci Total Environ 2012;416:97-104.

18 Goggins WB, Woo J, Ho S, Chan EY, Chau PH: Weather, season, and daily stroke admissions in Hong Kong. Int J Biometeorol 2012;56:865-872.

19 Hori A, Hashizume M, Tsuda Y, Tsukahara T, Nomiyama T: Effects of weather variability and air pollutants on emergency admissions for cardiovascular and cerebrovascular diseases. Int J Environ Health Res 2012;22: 416-430.

20 Ebi KL, Exuzides KA, Lau E, Kelsh M, Barnston A: Weather changes associated with hospitalizations for cardiovascular diseases and stroke in California, 1983-1998. Int J Biometeorol 2004;49:48-58.

21 Coelho FM, Santos BF, Cendoroglo Neto M, Lisboa LF, Cypriano AS, Lopes TO, Miranda MJ, Avila AM, Alonso JB, Pinto HS: Temperature variation in the 24 hours before the initial symptoms of stroke. Arq Neuropsiquiatr 2010;68:242-245.

22 Rothwell PM, Wroe SJ, Slattery J, Warlow CP: Is stroke incidence related to season or temperature? The Oxfordshire Community Stroke Project. Lancet 1996;347:934-936.

23 Field TS, Hill MD: Weather, chinook, and stroke occurrence. Stroke 2002;33:1751-1757.

24 Michelozzi P, Accetta G, De Sario M, D’Ippoliti D, Marino C, Baccini M, Biggeri A, Anderson HR, Katsouyanni K, Ballester F, Bisanti L, Cadum E, Forsberg B, Forastiere F, Goodman PG, Hojs A, Kirchmayer U, Medina S, Paldy A, Schindler C, Sunyer J, Perucci CA: High temperature and hospitalizations for cardiovascular and respiratory causes in 12 European cities. Am J Respir Crit Care Med 2009;179:383-389.

25 Cowperthwaite MC, Burnett MG: An analysis of admissions from 155 United States hospitals to determine the influence of weather on stroke incidence. J Clin Neurosci 2011;18:618-623.

26 Turner LR, Barnett AG, Connell D, Tong S: Ambient temperature and cardiorespiratory morbidity: a systematic review and meta-analysis. Epidemiology 2012;23:594-606.

27 Oudin A, Stromberg U, Jakobsson K, Stroh E, Bjork J: Estimation of short-term effects of air pollution on stroke hospital admissions in southern Sweden. Neuroepidemiology 2010;34:131-142.

-28 Wellenius GA, Burger MR, Coull BA, Schwartz J, Suh HH, Koutrakis P, Schlaug G, Gold DR, Mittleman MA: Ambient air pollution and the risk of acute ischemic stroke. Arch Intern Med 2012;172:229-234.

29 Brook RD, Rajagopalan S, Pope CA, 3rd, Brook JR, Bhatnagar A, Diez-Roux AV, Holguin F, Hong Y, Luepker RV, Mittleman MA, Peters A, Siscovick D, Smith SC, Jr, Whitsel L, Kaufman JD: Particulate matter air pollution and cardiovascular disease: an update to the scientific statement from the American Heart Association. Circulation 2010;121:2331-2378.

-30 Kalkstein LS, Valimont KM: An evaluation of summer discomfort in the United States using a relative climatological index. Bull Am Meteorol Soc 1986;67:842-848.

-31 Madrigano J, Baccarelli A, Mittleman MA, Wright RO, Sparrow D, Vokonas PS, Tarantini L, Schwartz J: Prolonged exposure to particulate pollution, genes associated with glutathione pathways, and DNA methylation in a cohort of older men. Environ Health Perspect 2011;119:977-982.

-32 Levy D, Lumley T, Sheppard L, Kaufman J, Checkoway H: Referent selection in case-crossover analyses of acute health effects of air pollution. Epidemiology 2001;12:186-192.

33 Lumley T, Levy D: Bias in the case-crossover design: implications for studies of air pollution. Environmetrics 2000;11:689-704.

34 Schwartz J, Zanobetti A, Bateson TF: Morbidity and mortality among elderly residents in cities with daily pm measurements; revised analyses of time-series studies of air pollution and health special report. Boston, Health Effects Institute, 2003, pp 25-58.

-35 Zanobetti A, O’Neill MS, Gronlund CJ, Schwartz JD: Summer temperature variability and long-term survival among elderly people with chronic disease. Proc Natl Acad Sci USA 2012;109:6608-6613.

-36 Adams HP, Jr, Bendixen BH, Kappelle LJ, Biller J, Love BB, Gordon DL, Marsh EE, 3rd: Classification of subtype of acute ischemic stroke. Definitions for use in a multicenter clinical trial. TOAST. Trial of Org 10172 in Acute Stroke Treatment. Stroke 1993;24:35-41.

37 R Development Core Team: R: A language and environment for statistical computing. Vienna, R Foundation for Statistical Computing, 2008.

38 Astrom DO, Forsberg B, Rocklov J: Heat wave impact on morbidity and mortality in the elderly population: a review of recent studies. Maturitas 2011;69:99-105.

-39 O’Neill MS, Hajat S, Zanobetti A, Ramirez-Aguilar M, Schwartz J: Impact of control for air pollution and respiratory epidemics on the estimated associations of temperature and daily mortality. Int J Biometeorol 2005; 50:121-129.

40 Basu R, Feng WY, Ostro BD: Characterizing temperature and mortality in nine California counties. Epidemiology 2008;19:138-145.

41 Anderson BG, Bell ML: Weather-related mortality: how heat, cold, and heat waves affect mortality in the United States. Epidemiology 2009;20:205-213.

42 Mercer JB, Osterud B, Tveita T: The effect of short-term cold exposure on risk factors for cardiovascular disease. Thromb Res 1999;95:93-104. 
Mostofsky et al.: Short-Term Changes in Ambient Temperature and Risk of Ischemic Stroke

43 Halonen JI, Zanobetti A, Sparrow D, Vokonas PS, Schwartz J: Relationship between outdoor temperature and blood pressure. Occup Environ Med 2011;68:296-301.

44 Schauble CL, Hampel R, Breitner S, Ruckerl R, Phipps R, Diaz-Sanchez D, Devlin RB, Carter JD, Soukup J, Silbajoris R, Dailey L, Koenig W, Cyrys J, Geruschkat U, Belcredi P, Kraus U, Peters A, Schneider AE: Short-term effects of air temperature on blood markers of coagulation and inflammation in potentially susceptible individuals. Occup Environ Med 2012;69:670-678.

45 Hong YC, Kim H, Oh SY, Lim YH, Kim SY, Yoon HJ, Park M: Association of cold ambient temperature and cardiovascular markers. Sci Total Environ 2012;435-436:74-79.

46 Halonen JI, Zanobetti A, Sparrow D, Vokonas PS, Schwartz J: Associations between outdoor temperature and markers of inflammation: a cohort study. Environ Health 2010;9:42.

47 Brook RD, Weder AB, Rajagopalan S: 'Environmental hypertensionology' the effects of environmental factors on blood pressure in clinical practice and research. J Clin Hypertens (Greenwich) 2011;13:836-842.

48 Halonen JI, Zanobetti A, Sparrow D, Vokonas PS, Schwartz J: Outdoor temperature is associated with serum HDL and LDL. Environ Res 2011;111:281-287.

49 von Klot S, Paciorek C, Melly S, Coull B, Dutton J, Schwartz J: Association of temperature at residence vs central site temperature with mortality in Eastern Massachusetts - a case crossover analysis. Epidemiology 2009; 20:S75.

50 O’Neill MS, Zanobetti A, Schwartz J: Disparities by race in heat-related mortality in four US cities: the role of air conditioning prevalence. J Urban Health 2005;82:191-197.

-51 Klepeis NE, Nelson WC, Ott WR, Robinson JP, Tsang AM, Switzer P, Behar JV, Hern SC, Engelmann WH: The National Human Activity Pattern Survey (NHAPS): a resource for assessing exposure to environmental pollutants. J Expo Anal Environ Epidemiol 2001;11:231-252. 